\title{
Carboxytherapy - a non-invasive method in aesthetic medicine and dermatology, and the combined usage of carboxytherapy and PRP in the periorbital area
}

\author{
Zelenková $\mathbf{H}^{*}$ \\ Private Department of Dermatovenereology - DOST Svidnik, Slovakia
}

\begin{abstract}
The work has been elaborated to provide basic information on carboxytherapy - controlled application of purified carbon dioxide in aesthetic medicine and dermatology. It introduces its basic indications and contraindications as well as the advantages and the possibilities of combining the said method with other therapeutic modalities.
\end{abstract}

\section{Introduction}

The usage of carbon dioxide in medicine and balneotherapy has a long tradition indeed. In ancient times already, baths were taken in volcanic fumes and sulphur tar (in Europe in for example in the caves near Naples). Later carbon dioxide was used in combination with hydrogen sulphide. Targeted therapeutic use of purified carbon dioxide started in 1720 in Pyrmont Spa. With time, more and more spas started using offering therapy, such as Meiberg and Mariánské Lázně. In 1818 first publications by Professor K. J. Heidler appeared about the positive influence of the so called gas baths on the human organism [1].

\section{History}

Carboxytherapy - therapeutically applied carbon dioxide injections have been used in balneotherapy since 1932, thanks to the balneotherapists from the French Royat Spa. Since then, the number of publications dealing with carboxytherapy has been increasing every year, advocating the great effects of this therapeutic modality. In balneotherapy, the said "gas injections" are applied predominantly to treat joint problems and impaired blood circulation in the lower extremities (ischemic disease) and in the skin of diabetic patients, but also in some patients with systemic vascular diseases and diseases of the heart (bradycardia, low blood pressure) [2-8]. In the last two years, however, this treatment modality has become the centre of attention as a unique method applicable in dermatology, aesthetic dermatology and anti-aging medicine [1-5,8-19].

The method itself is promoted widely at world congresses dealing with ageing as well as at many renowned clinics specialising in skin rejuvenation as a method that is clearly minimum invasive, easy to tolerate by the patients, and brings maximum effects without the risk of side effects. In Europe, the method is subject of research of the University of Siena, Italy, and the Center for Microangiology and Microcirculation of the University of Milan and Pavia, Italy, and at clinics in Austria and Hungary, Czech Republic, and Slovakia. The method is promoted and used in many countries around the world (Australia, Korea, Singapore, and South America).

\section{Definition}

Carboxytherapy stands for controlled application of purified carbon dioxide into various parts of the human body with the aim of improving blood circulation in the tissues, improve skin elasticity, reduce local fat deposits, or even improve the cosmetic effect after liposuction [1-3,6,8,9,11,12,14-17].

In the Italian city Siena an international society was established, dealing with carboxytherapy in a complex way (G.I.S.C. - International Scientific Carbondioxide Therapy Group). The GISC areas of research are to be divided into the following parts:

- unambiguous definition of the mechanism of action

- optimisation of methodology

- definition of possible fields of usage

- gathering of information in order to elaborate precise application guidelines

- $\quad$ study of the potential of carboxytherapy used in combination with other techniques (such as surgical and dermatological techniques)

\section{Mechanism of action of $\mathrm{CO}_{2}$}

In the tissue, carbon dioxide reacts with water molecules, and molecular carbonic acid is formed. This acid reduces the tissue $\mathrm{pH}$. Here, the Bohr Effect comes into play - the lower the $\mathrm{pH}$, the weaker the bond between haemoglobin and oxygen. While carboxytherapy is being applied, the release of oxygen from haemoglobin is increased. In addition, at the level of $\mathrm{pH}$ of 6.8 and less the permeability of capillary walls is increased. At the $\mathrm{pH}$ of 6,5 , and less the flexibility of collagen fibres is increased, while their firmness is decreased [2-

Correspondence to: Zelenková H, Private Department of Dermatovenereology - DOST Svidnik, Slovakia, Email zelenkova@vl.sk

Received: January 04, 2017; Accepted: February 09, 2017; Published: February 13,2017 

periorbital area

$4,8-10,13]$. Other chemical reactions include the reduction of divalent calcium ions and the split of carbonic acid to $\mathrm{H}+$ a $\mathrm{HCO} 3$ - resulting in the formation of calcium hydrogen carbonate- $\mathrm{Ca}\left(\mathrm{HCO}_{3}\right)^{2}$, sodium hydrogen carbonate, and potassium hydrogen carbonate $\left(\mathrm{NaHCO}_{3}\right.$ and $\mathrm{KHCO}_{3}$ ).

As a reaction, $\mathrm{pH}$ becomes alkaline, which finally leads to an analgesic and spasmolytic effect. The tonus of arteries and capillaries is decreased and the skin temperature is increased by $1^{\circ} \mathrm{C}$. This effect combined with the changed activity of nerve endings improves the trophicity of the treated localities. At the same time, oxidation of fats from the fatty cells is activated, whereby some authors state that there is direct lipolytic effect on adipocytes $[6,8,9,12,20]$. The residual $\mathrm{CO}_{2}$ is exhaled by the lungs. Other effects of carboxytherapy, the overall effects are also described, which lead to dilatation of coronary arteries, bradycardia and decreased blood pressure [8].

\section{Indications}

Based on the latest knowledge it is only logical that carboxytherapy is gradually becoming the centre of attention of renowned experts and celebrities who prefer this treatment modality to those more aggressive and invasive rejuvenation methods (lasers, gold threads lifts, face lifts, thermage, and others). This rejuvenation method is popular with clients who would like to limit the effects of ageing, reduce the appearance of stretch marks, enhance the effects of liposuction, treat cellulite, or

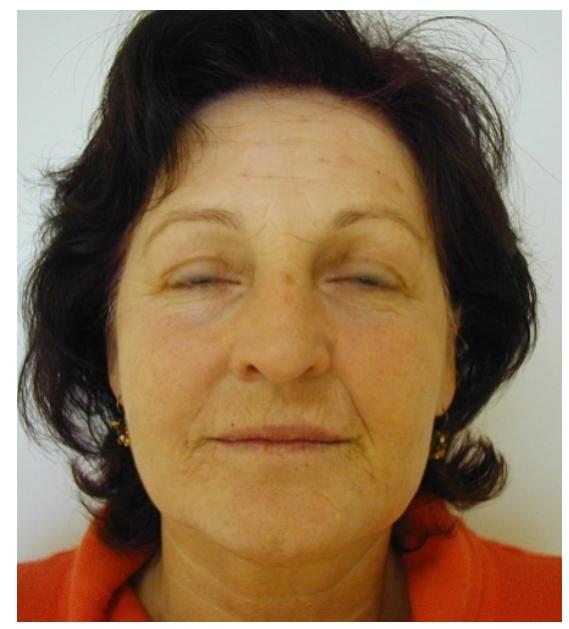

Figure I. Patient before carboxytherapy - rejuvenation.

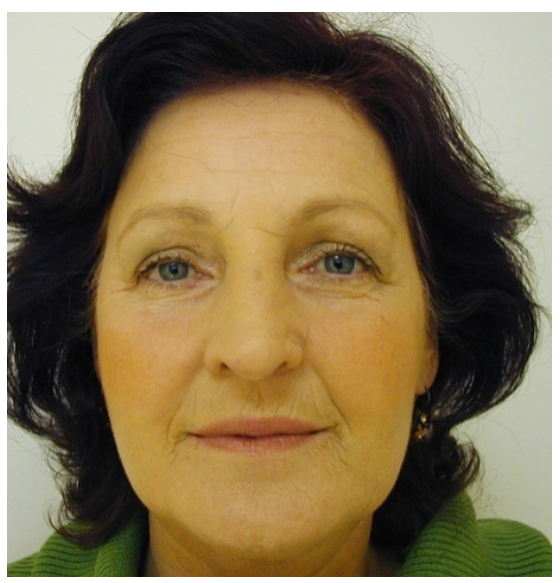

Figure 2. Patient after 3 sessions of carboxytherapy - rejuvenation.

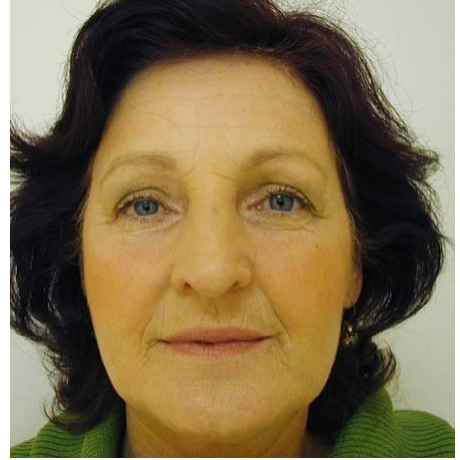

Figure 3. Patient before carboxytherapy - rejuvenation.

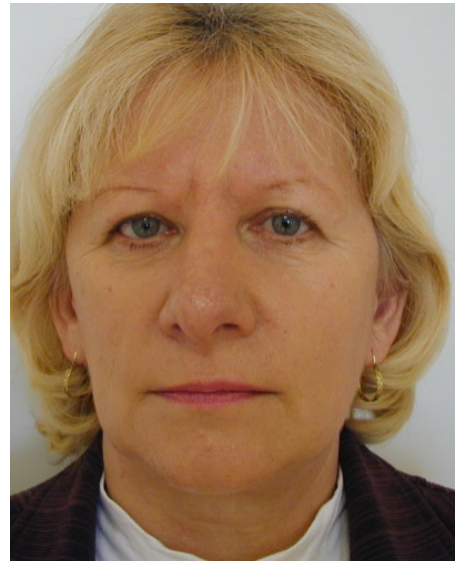

Figure 4. Patient after 3 sessions of carboxytherapy - rejuvenation.

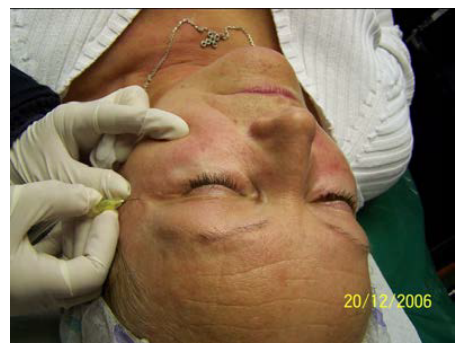

Figure 5. Application of carboxytherapy in periorbital area.

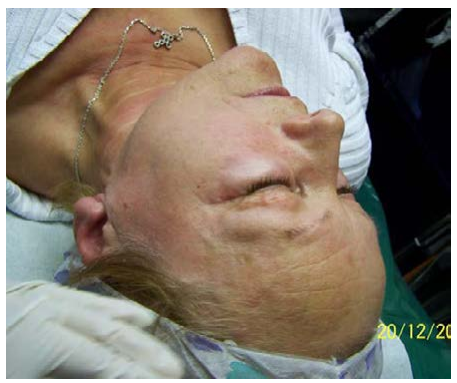

Figure 6. The same patient - mild oedema resolves in several minutes.

shape directly the problem areas of the human body (thighs, hips, abdomen) [1,6,9,11,12,14-17].

In aesthetic dermatology the vasodilatation effect is taken advantage of together with the effect on the intradermal collagen reorganisation. This effect is visible quite early (usually after two sessions, for example in the course of 7-14 days). The tonus of the skin as well as its aesthetic 


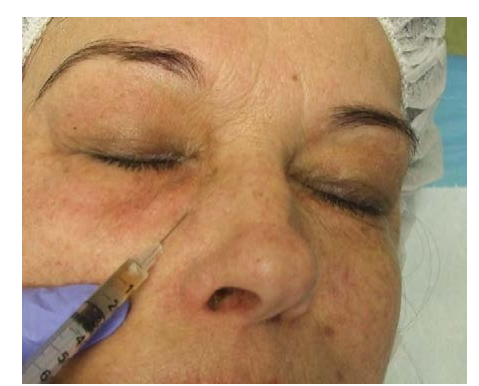

Figure 7. Application of PRP in periorbital area

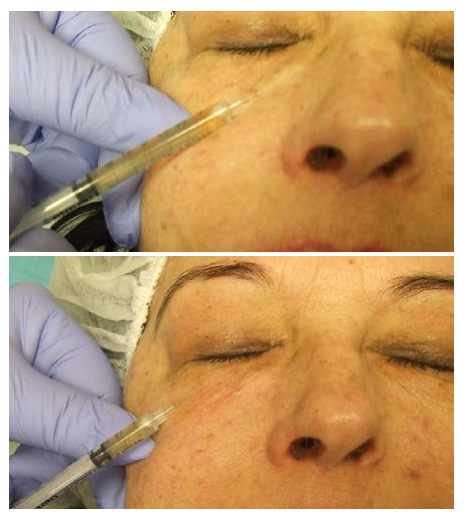

Figure 8. The same patient - treatment procedure.

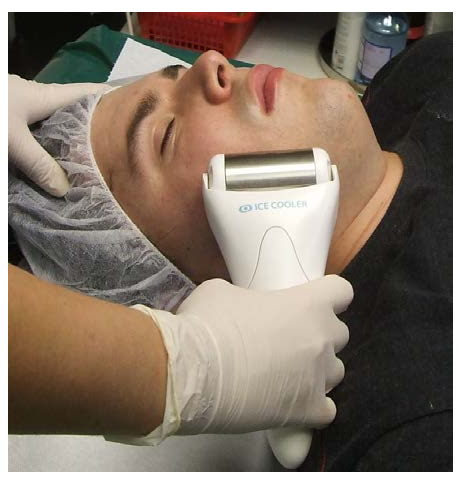

Figure 9. Ice Cooler pro.

parameters improves visibly. Carbon dioxide is used to treat double chin, neck, décolleté, and the lax skin on the abdomen, arms (even after brachioplasty), and inner thighs as part of body contouring, and in post liposuction conditions, and to treat lipomatosis, stretch marks, and the skin on the glabella, crow's feet, fine wrinkles around the eyes, and the lower lids - however, here the application of requires a lot of experience.

For a dermatologist carboxytherapy is a therapeutic modality to be used in patients with poor healing leg ulcers, in patients with peripheral diabetic complications, in therapy of hypertrophic and keloid scars, ill healing surgical wounds, Raynaud's disease, Morbus Burger, acrocyanosis, lymphoedema, healing of the skin after the application of skin implants. Carboxytherapy is also effective in the therapy of some symptoms of flexural psoriasis, especially in combination with traditional methods, in circumscript sclerodermia, or in alopecia difusa and alopecia areata $[1-4,8,10,14,16-18]$.

\section{Contraindications}

Severe ischemic heart disease, acute embolism, thrombophlebitis and phlebothrombosis, gangrene, renal failure, untreated high blood pressure, stroke, pregnancy, lactation, severe adiposity (after body contouring), acute infectious disease, fever, and blood clotting.

Other contraindications also include unrealistic expectations on the side of the patient and high biological age.

\section{Application}

The application of carbon dioxide in dermatology and aesthetic medicine requires special devices (at our clinic we use the device Carbomed by an Italian company, Carbossiterapia Italiana, and an original Slovak device iNCO). The device is connected through a reduction valve directly with the bomb filled with purified $\mathrm{CO}_{2}$. The gas flows under the pressure of 2.5 to 3.5 bar (i.e. $250000-350000 \mathrm{~Pa}, 1875$ 2625 Torr). For the application itself the parameters (gas flow in $\mathrm{ml} /$ min, overall volume in $\mathrm{ml}$ ) are selected and set individually depending on indication and site. Injections are made using a 30G mesotherapy needle, which may be e 4,12 or $13 \mathrm{~mm}$ long. The gas instillation is controlled by using a foot pedal.

The injection angle is of great importance. In superficial subcutaneous application the angle comprises $30^{\circ}$. The elevation of the tissue is visible, which is used to treat to skin problems on the face and décolleté and to improve the appearance of stretch marks.

In deeper intradermal application of gas the injection angle comprises $45^{\circ}$, whereby this type of application is used to reduce fatty tissue.

Depending on the expertise of the therapist and on the extent of the treated localities one session takes between 20-40 minutes, whereby the total volume of applied carbon dioxide amounts to $5-50 \mathrm{ml}$ on the face (in physiotherapy higher volumes are injected, of about 20-200 ml per session). On the trunk and the extremities, the volumes range from 200 to $1000 \mathrm{ml}$. It is necessary to avoid or eliminate application into vessels (as it causes hematoma).

\section{The number and frequency of applications}

The number of applications is very much dependent on the indication as well as the treated locality. It is necessary to make the patient aware of the fact that after one session the effect shall not be as excellent as they might unrealistically expect. It is necessary to repeat the application once or twice a week. However, most patients report a positive effect and a change in the aesthetic parameters of the skin already after the first or second session. In body shaping for example of the trunk, abdomen, arms, and thighs the effects are visible after 6 to 8 sessions. The total number of sessions in those localities usually starts with 10 and depends on the effects already achieved and to be achieved.

Dermatologic indications usually require a higher number of sessions. In our experience, positive effects are observable in ulcera cruris, flexural psoriasis and alopecia around after 15 - 30 sessions. It is necessary to state that the patients actually require to be treated since they consider the effects excellent.

\section{Sensations that accompany the sessions}

\section{In the course of the application}

Minimum pain accompanying the injection itself (controlled, and very transient), cracking in the subcutis (resolves within 1 hour and poses no reason to discontinue the application), freezing, burning, itching (resolves within seconds). The tension in the skin is very slight (as $\mathrm{CO}_{2}$ penetrates the tissue), the swelling resolves within seconds. 


\section{Immediately after application}

Heat wave, itching, and burning sensation (analgesic effect of $\mathrm{CO}_{2}$, on the depolarisation of nerve membranes). These sensations usually last for a very limited period of time. The heat wave caused by vasodilatation subsides in about $10-20 \mathrm{~min}$. It is only in very sensitive individuals that these sensations last for up to 24 hours after the intervention. If a vessel is hit occasionally, hematoma or ecchymosis occur ( $5 \%$ of all cases). Eyelid oedema may persist for up to 4 days.

\section{The combined usage of carboxytherapy and PRP in the periorbital area}

In practice, use optimal cooling with IceCooler pro in sensitive patients before carboxytherapy. IceCooler pro is a sophisticated, extraordinarily effective and simple system usable in the office or in home care. The purpose of IceCooler pro use is cooling and healing.

Carboxytherapy in periorbital area - educate your patients and don't apply high volumes of $\mathrm{CO}_{2}$. Please understand that the method is easy to master and quick and it is very effective. Oedema may develop after the $1^{\text {st }}$ application, but resolves within 10 minutes. The needle is inserted $1.5-2 \mathrm{~cm}$ from the external eye corner, very superficially, strictly in an angle of 30 degrees. The filling of the upper and lower eyelid is rapid and "dramatic". 2 more injections every $2 \mathrm{~cm}$ are made. Despite oedema the patient feels no pain, treat one side first completely. Continue on the glabella and forehead. Only then continue on the cheeks. By the time you finish the treatment of the whole face, there is no oedema in the periorbital area.

For carboxytherapy in periorbital area combined with PRP select the right order of sessions. In seborrheic skin first treat the periorbital area with PRP, perform 2 sessions in a 14 day interval. Start from the inner to the outer eye corner, and apply a suitable amount of PRP by means of retrograde injection. Be very careful not to cause multiple hematoma. Around the outer eye corner apply PRP into the wrinkles, use mild massage and a PRP mask, and if you combine Carboxytherapy with PRP in periorbital area, cool the treated areas with IceCooler ${ }^{\circledR}$ pro.

In patient with "porcelain skin" first apply carboxytherapy in 2 sessions at an interval of 1 week. One week after the first session apply PRP, and repeat 2 times at an interval of 14 days. Very good and satisfactory aesthetic effects can be achieved. The procedure can be repeated after 2-3 months. The patients are advised to use oral antioxidants and HA preparations. If the effect is not satisfactory or too transient, we recommend stem cell therapy after 4 months. PRP:

Own experience Carboxytherapy in periorbital combined with

We have treated 48 patients so far; in 40 patients the effect was very good and satisfactory. In 4 patients the effect was good, but carboxytherapy was repeated (the patients required more treatments), 4 patients only reacted to the treatment of the periorbital area with PRP $(18,19,20)$

\section{Conclusion}

The advantages of carboxytherapy: in adequate indications, this method seems to be absolutely versatile, safe, physiological, selective, and minimum invasive, covering a very broad therapeutic range. The method is not money consuming, and thus very affordable for the patient.

The improvement achieved by using this method in aesthetic dermatology is preserved for a number of months ( $3-6$ or more) and depends not only on the effect itself but also on the lifestyle and on further care.

Carboxytherapy may be combined with a number of other techniques (mesotherapy, superficial peels, microdermabrasion, photorejuvenation, PRP and others). It is necessary to keep in mind that for example in combination with botulinum toxin it is possible that the effects of botulinum toxin are (not always) decreased.

In some parameters - such as the rejuvenation of some facial areas, the effects and the safety of application of carbon dioxide are superior to the application of Botulinum toxin. In combination with PRP, excellent effects can be achieved.

The disadvantage is the necessity to repeat the application.

The treatments in periorbital area are technically demanding in the field of aesthetic dermatology. If you choose adequate material, appropriate technique, and an educated patient, the effects you achieve can be very satisfactory.

\section{References}

1. Koutná N (2006) Carboxytherapy--a new non-invasive method in aesthetic medicine. Cas Lek Cesk 145: 841-843. [Crossref]

2. Hartmann BR, Bassenge E, Pittler M (1997) Effect of carbon dioxide-enriched water and fresh water on the cutaneous microcirculation and oxygen tension in the skin of the foot. Angiology 48: 337-343. [Crossref]

3. Hartmann BR, Bassenge E, Hartmann M (1997) Effect of serial percutaneous application of carbon dioxide in intermittent caludication: result of a controlled trial. Angiology 48: 957-963. [Crossref]

4. Ito T, Moore JI, Koss MC (1995) Topical application of CO2 stage II peripheral occlusive arterial disease. Angiology.

5. Krížek V (1987) Picazy z dejin lázenství. Avicennum Praha 41-42

6. Liebaschoff G (2006) Carboxytherapy. Cellulite - Pathophysiology and Treatment, Taylor \& Francis Group. Pp: 197-210

7. Rychlíková E (1987) Manuální medicína. Avicenum. 140

8. Savin E, Bailliart O, Bonnin P, Bedu M, Cheynel J, et al. (1995) Vasomotor effects of transcutaneous CO2 in stage II peripheral occlusive arterial disease. Angiology 46: 785-791. [Crossref]

9. D'Aniello BC, Lattarulo P, Bosi B, Gromaldi L (1999) Il rulo della carbossiterapia nella strategia terapeutica della lipimatosi Multipla Simmetrica. Riviera Italiana di Chirurgia Plastica 31:265-269.

10. D'Arcangelo D, Facchiano F, Barlucchi LM, Melillo G, Illi B, et al (2000) Acidosis Inhibits Endothelial Cell Apoptosis and Function and Induces Basic Fibroblasts Growth Factor and Vascular Endothelial Growth Factor Expression. Circulation Research 86: 312.

11. Brandi C, D'Aniello C, Grimaldi L, Caiazzo E, Stanghellini E (2004) Carbon dioxide therapy: effects on skin irregularity and its use as a complement to liposuction. Aesthetic Plast Surg 28: 222-225. [Crossref]

12. Brandi C, D'Aniello C, Grimaldi L, Bosi B, Dei I, et al (2001) Carbon Dioxide Therapy in the Treatment of Localised Adiposities: Clinical Study and Histopathological Correlations. Aesth Plast Surg 25: 179-174. [Crossref]

13. Hinz B1, Mastrangelo D, Iselin CE, Chaponnier C, Gabbiani G (2001) Mechanical Tension Controls Granulation Tissue Contractile Activity and Myofibroblast Differentiation. Am J Pathology 159: 1009-1020. [Crossref]

14. Pintér L (2007) Carboxytherapy. Estetická chirurgie. Kapitola 8, p. 424, Edice plastické chirurgie, vydavatelstvo Nukleus 2007

15. Zelenková H, Stracenská J (2008) Carboxytherapy - a novel non-invasive method in aesthetic medicine. VI. World Congress IACD 2008, June 18-20 2008, Lisbon, Portugal.

16. Zelenková H, Stracenská J (2008) Carboxytherapy in Aesthetic medicine. COSMODERM XIII, Congress ESCAD, Athens

17. Zelenková H, Stracenská J (2008) Combined methods in Aesthetic dermatology. 
Zelenková H (2017) Carboxytherapy - a non-invasive method in aesthetic medicine and dermatology, and the combined usage of carboxytherapy and PRP in the periorbital area

\section{COSMODERM XIII, Congress ESCAD, Athens.}

18. Zelenkova H (2013) Karboxiterapia -neinvazivnyj metod v esteticeskoj medicine i dermatologii. Oblik, No.3: 72-75
19. Zelenkova H (2014) The combined usaje of carboxytherapy and PRP in the periorbital area. XV Kongres Sztowarzyszenia lekarzy dermatologie estetycznych. 7.-marca 2014 Warszawa, Hotel Mariot.

20. Marek J, Kolárová M (2012) Plynové injekce. Praha, Triton 2002, 14-15.

Copyright: @2017 Zelenková H. This is an open-access article distributed under the terms of the Creative Commons Attribution License, which permits unrestricted use, distribution, and reproduction in any medium, provided the original author and source are credited. 